\section{Os biomarcadores e sua aplicação na avaliação da exposição aos agentes químicos ambientais}

\section{Biomarkers for evaluating exposure to chemical agents present in the environment}

\section{Leiliane Coelho André Amorim}

Departamento de Análises Clínicas e Toxicológicas

Faculdade de Farmácia

Universidade Federal de Minas Gerais

Av. Olegário Maciel, 2360

CEP 30180-112 - Bairro de Lourdes

Belo Horizonte, MG - Brasil

leiliane@dedalus.lcc.ufmg.br

\section{Resumo}

A Saúde Ambiental tem como um de seus objetivos, a prevenção dos danos à saúde causados por contaminantes químicos presentes no meio ambiente, fazendo com que os níveis desta exposição sejam mantidos em valores que não constituam um risco inaceitável. Para isso, tornam-se necessárias a identificação e quantificação deste risco através da avaliação biológica da exposição humana.

Este é um artigo de revisão que busca apresentar conceitos e concepções que abrangem o uso dos parâmetros biológicos com a finalidade de avaliar a exposição às substâncias químicas e estimar o risco das populações expostas. Os biomarcadores podem ser usados para vários propósitos, dependendo da finalidade do estudo e do tipo da exposição e podem ser classificados em três tipos: de exposição, de efeito e de suscetibilidade, os quais são instrumentos que possibilitam identificar a substância tóxica ou uma condição adversa antes que sejam evidenciados danos à saúde. Novos parâmetros são apresentados, como os biomarcadores de neurotoxicidade (ou marcadores substitutos), que têm como desafio detectar ações precoces de agente químicos que agem no sistema nervoso central através da identificação de indicadores presentes no sistema periférico, que são equivalentes aos parâmetros presentes no tecido nervoso.

Palavras-chave: Exposição às substâncias químicas. Biomarcadores de dose interna. Biomarcadores de efeito. Biomarcadores de suscetibilidade. Biomarcadores de neurotoxicidade. 


\section{Abstract}

One of goals of environmental health is to prevent disease and injuries caused by chemical pollutants present in the environment. The main objective is to keep chemical exposure to an acceptable level that does not imply in risk. In order to accomplish that, it is necessary to identify and quantify chemical risk through biological assessment of human exposure.

In this review, we present concepts and principles covering the utilization of biological indicators in order to evaluate exposure to chemicals and risk to human health.

The use of biomarkers with different purposes may be classified in to three types: of exposure (internal dose), of effect and of susceptibility, which are means for identifying toxic substances or hazardous conditions before demage to health has occurred. New parameters are presented, such as biomarkers of neurotoxicity (or surrogate indicators), whose purpose is to detect early action of chemicals on the nervous system, through the determination of indicators present in peripheral body fluids, which are equivalent parameters of the nervous tissue.

Key Words: Chemical exposure. Biomarkers of internal dose. Biomarkers of effect. Biomarkers of susceptibility. Surrogate indicators.

\section{Introdução}

Diante do processo de modernização e suas conseqüências, incluindo as desigualdades sociais, poluição e degradação ambiental; a crescente concentração de poder econômico e político; a industrialização acelerada e o uso de novos métodos tecnológicos na agricultura, a espécie humana está sujeita a uma série de riscos decorrentes dos fatores ambientais envolvidos, tais como: fatores psicológicos, fatores acidentais, fatores biológicos, fatores físicos e fatores químicos.

No que se refere aos fatores químicos, são inúmeros os agentes potencialmente tóxicos, aos quais a população está exposta cotidianamente, através do ar que respira, da água que bebe e do alimento que ingere, representando as principais fontes de exposição. A avaliação da exposição aos agentes químicos constitui um importante aspecto para a saúde pública, tendo em vista a possibilidade de se prevenir ou minimizar a incidência de mortes ou doenças decorrentes da interação das substâncias químicas com o organismo humano.

A avaliação da exposição, associada aos conhecimentos relativos aos efeitos na saúde e os limites considerados seguros, permite estabelecer as prioridades e as formas de intervenção efetiva para proteger uma população dos riscos químicos. Os estudos dos efeitos das substâncias químicas sobre a saúde possibilita avaliar o risco da população exposta e constitui o primeiro passo na fixação de normas ambientais para um contaminante químico presente num meio. E para isso é importante conhecer a solidez e as limitações dos dados toxicológicos, assim como as informações disponíveis provenientes destes estudos ${ }^{1}$.

Alguns tipos de informações sobre os efeitos tóxicos de agentes químicos só podem ser obtidos mediante observações diretas no homem. Estes estudos, cuidadosamente controlados, são realizados com pequenas doses consideradas inócuas para alguns tipos de efeitos. Ou são realizados simplesmente por observações clínicas em in- 
divíduos, em geral expostos no trabalho às substâncias químicas ${ }^{2}$.

No entanto, as exposições controladas de seres humanos às substâncias perigosas ou potencialmente perigosas vêem-se restringidas por considerações éticas e, por isso, com grande freqüência se recorre a estudos em animais para predizer a reação humana aos efeitos destas substâncias. O grau de confiabilidade com o qual se pode estimar os riscos à saúde humana, tendo como base os testes de toxicidade realizados em animais, depende da qualidade dos dados, assim como da quantidade e dos tipos de testes realizados ${ }^{2}$.

Além destes estudos citados acima, os estudos epidemiológicos sobre as populações humanas podem estabelecer os riscos associados a um determinado agente químico. No entanto, ao estudar as substâncias químicas presentes no ambiente, a fragilidade principal destes estudos se deve a eles serem relativamente pouco eficazes para determinar se os efeitos observados na saúde são o resultado direto da exposição a uma substância química em particular. Pelo fato de de ser necessário ocorrer uma exposição a um agente químico durante um período longo para que possam ser observadas diferenças perceptíveis em uma população, a Epidemiologia não deve ser a base das decisões regulamentares ${ }^{2}$. Entretanto, a Epidemiologia Ambiental procura estabelecer associações entre a exposição aos agentes químicos e os efeitos adversos na saúde, presumivelmente causados por esta exposição ${ }^{1}$, desafiando os limites estabelecidos frente aos novos conhecimentos e possibilitando a proteção da saúde de populações expostas através do controle e da vigilância.

\section{Avaliação da exposição aos contaminadores químicos}

A detecção precoce de uma exposição perigosa pode diminuir significativamente a ocorrência de efeitos adversos na saúde. As informações provenientes da monitorização da exposição ambiental ou ocupacional possibilitam a implantação de medidas de pre- venção e controle apropriadas, sendo necessários: a definição dos níveis permissíveis de exposição, que, de acordo com os conhecimentos atuais, são estabelecidos para não causar efeitos adversos decorrentes da exposição química; e a avaliação regular dos possíveis riscos à saúde associados à exposição por comparação com estes limites permissíveis ${ }^{3}$.

A monitorização da exposição é um procedimento que consiste em uma rotina de avaliação e interpretação de parâmetros biológicos e/ou ambientais, com a finalidade de detectar os possíveis riscos à saúde. A exposição pode ser avaliada por medida da concentração do agente químico em amostras ambientais, como o ar (monitorização ambiental), ou através da medida de parâmetros biológicos (monitorização biológica), denominados indicadores biológicos ou biomarcadores. A Monitorização Biológica da exposição aos agentes químicos, propriamente dita, significa a medida da substância ou seus metabólitos em vários meios biológicos, como sangue, urina, ar exalado e outros (por exemplo, mercúrio na urina). Algumas vezes, o conceito de Monitorização Biológica é estendido para incluir também a detecção precoce de efeitos não adversos reversíveis (monitorização biológica de efeito) (por exemplo, ácido delta aminolevulínico na urina). A detecção de um efeito adverso (por exemplo, proteinúria aumentada) indica que a exposição é ou tem sido excessiva, e além disso tal medida é mais apropriada para ser incluída num programa de detecção precoce de prejuízo à saúde (vigilância da saúde), devido à exposição a uma determinada substância química, e não para fins de prevenção $0^{4,5}$.

A Avaliação Biológica da exposição às substâncias químicas só é possível quando estiverem disponíveis suficientes informações toxicológicas referentes ao mecanismo de ação e/ou à toxicocinética dos agentes químicos aos quais os indivíduos estão expostos. Quando a Monitorização Biológica está baseada na determinação da substância química ou do seu metabólito no meio biológico, torna-se essencial o conhecimento 
de como a substância é absorvida pelas diferentes vias; posteriormente, de como é distribuída para os diferentes compartimentos do organismo; de como é biotransformada; e, finalmente, de como é eliminada. Além de ser necessário saber também se a substância se acumula ou não no organismo ${ }^{3,6}$.

Da mesma forma, se a Monitorização Biológica estiver baseada na medida de uma alteração biológica do organismo, causada pelo agente químico, é necessário conhecer o processo da toxicodinâmica, ou seja, é preciso conhecer o mecanismo de ação da substância química para identificar quais são os efeitos não adversos decorrentes daquela ação $0^{3,6}$. Isso se faz necessário porque só a identificação e a medida de um efeito precoce, não adverso, podem ser usadas para fins de prevenção.

\section{Indicadores biológicos (ou biomarcadores)}

Vários são os parâmetros biológicos que podem estar alterados como conseqüência da interação entre o agente químico e o organismo; entretanto, a determinação quantitativa destes parâmetros usados como Indicadores Biológicos ou Biomarcadores, só é possível se existir correlação com a intensidade da exposição e/ou o efeito biológico da substância. Desta forma, o Biomarcador compreende toda substância ou seu produto de biotransformação, assim como qualquer alteração bioquímica precoce, cuja determinação nos fluidos biológicos, tecidos ou ar exalado, avalie a intensidade da exposição e o risco à saúde ${ }^{4}$.

\section{Seleção e validação dos biomarcadores}

O processo de seleção e validação dos indicadores biológicos requer cuidado em relação à especificidade e sensibilidade, assim como a medida da exposição e a manifestação dos efeitos observados. A validação é um processo utilizado para estabelecer a relação quantitativa e qualitativa do biomarcador com a exposição, em função da substância química e do objetivo selecionado ${ }^{7}$.
Para que uma substância química, seu metabólito ou uma alteração biológica sejam validados e/ou propostos como biomarcador, é desejável que o mesmo apresente as seguintes características: ${ }^{7}$

- A quantificação do indicador deve:

- refletir a interação (qualitativa ou quantitativa) do sistema biológico com a substância química;

- ter conhecida e apropriada sensibilidade e especificidade para a interação;

- ser reprodutível qualitativamente e quantitativamente.

- Estar contido em um meio biológico acessível de análise, considerando a necessidade de manutenção da integridade da amostra entre a coleta e o procedimento analítico, e de preferência não ser invasivo.

- A medição analítica tem que apresentar exatidão e precisão adequadas.

- Conhecer os valores normais do indicador em populações não expostas ao agente químico de interesse, assim como as variações intra e interindividuais.

\section{Aplicação dos Biomarcadores}

Os Biomarcadores podem ser usados para vários propósitos, dependendo da finalidade do estudo e do tipo da exposição química. Podem ter como objetivos avaliar a exposição (quantidade absorvida ou dose interna), avaliar os efeitos das substâncias químicas e avaliar a suscetibilidade individual. Além disso, podem ser utilizados independentemente da fonte de exposição, seja através da dieta, do meio ambiente geral ou ocupacional. A utilização destes Biomarcadores pode ter como finalidade elucidar a relação causa-efeito e dose-efeito na avaliação de risco à saúde; para fins de diagnóstico clínico; e para fins de monitorização biológica, realizada de maneira sistemática $\mathrm{e}$ periódica ${ }^{7}$.

O uso dos Biomarcadores na avaliação de risco fornece uma ligação crítica entre a exposição à substância química, dose interna e prejuízo à saúde, e eles são valiosos na avalia- 
ção de risco. Contudo, existe uma necessidade de identificar e validar para cada sistema orgânico estes parâmetros característicos que são indicativos de indução de disfunção orgânica, alteração clínica e toxicidade patológica, além de estabelecer a especificidade e sensibilidade de cada biomarcador e seu método para determinação? .

Os Biomarcadores podem ser utilizados no diagnóstico clínico para?:

- confirmar diagnóstico de intoxicação agudo ou crônico;

- avaliação da efetividade de tratamento;

- avaliar o prognóstico de casos individuais.

Os biomarcadores podem ser usados ainda na atividade de monitorização para confirmar a exposição individual ou de uma população a uma determinada substância química e avaliar o risco, quando comparados com uma referência apropriada. Sabendo-se que a Monitorização Ambiental é realizada para reduzir as exposições ocupacionais e comprovar se as medidas preventivas adotadas no ambiente são satisfatórias, a Monitorização Biológica tem como meta principal verificar se existe segurança enquanto ocorre a presença do agente químico no ambiente de trabalho, em exposições presentes, e inclusive passadas, para evitar a ocorrência de efeitos adversos à saúde ${ }^{7}$.

A realização da Monitorização Biológica da exposição ocupacional permite avaliar a exposição global ao agente tóxico, além de considerar os aspectos individuais de exposição aumentada provenientes, por exemplo, de esforço físico; e as suscetibilidades biológicas ${ }^{3}$.

\section{Classificação dos Biomarcadores}

Independente da finalidade e aplicação dos Biomarcadores, eles podem ser classificados em 3 tipos, a saber:

- Os Biomarcadores de Exposição podem ser usados para confirmar e avaliar a exposição individual ou de um grupo, para uma substância em particular, estabelecendo uma ligação entre a exposição externa e a quantificação da exposição interna.
- Os Biomarcadores de Efeito podem ser usados para documentar as alterações pré-clínicas ou efeitos adversos à saúde decorrentes da exposição e absorção da substância química. Dessa forma, a ligação dos biomarcadores entre exposição e efeitos contribui para a definição da relação dose-resposta.

- Os Biomarcadores de Suscetibilidade permitem elucidar o grau de resposta da exposição provocada nos indivíduos ${ }^{6,7}$.

\section{Biomarcadores de exposição (ou dose interna)}

O indicador biológico de exposição estima a dose interna, através da determinação da substância química ou de seu produto de biotransformação em fluídos biológicos, como sangue, urina, ar exalado e outros, possibilitando quantificar a substância no organismo, quando a toxicocinética é bem conhecida $^{8}$.

Os biomarcadores de exposição refletem a distribuição da substância química ou seu metabólito através do organismo, e por isso são identificados como dose interna. Conseqüentemente, a dose externa se refere à concentração do agente químico presente no ambiente em contato com o organismo. Teoricamente, a distribuição da substância no organismo pode ser traçada através de vários níveis biológicos, como tecidos e células, até seu alvo definitivo ${ }^{7}$, como mostra a Figura 1.

Da quantidade total absorvida da SQ, somente uma porção chegará até o tecido alvo. Uma porção alcançará o sítio crítico (sítio alvo) na macromolécula, com somente uma fração da última quantidade agindo como a dose biologicamente ativa. A escolha dos Biomarcadores para cada uma destas formas de dose interna seria útil para avaliação do risco ${ }^{9}$. Na figura, o afunilamento da base, a diminuição da quantidade total absorvida para cada nível, a maneira como ocorre a distribuição e o metabolismo, demonstram a diminuição da concentração da dose interna que alcança o tecido alvo (célula ou sítio crítico ${ }^{7}$. 
EXPOSIÇÃO EXTERNA

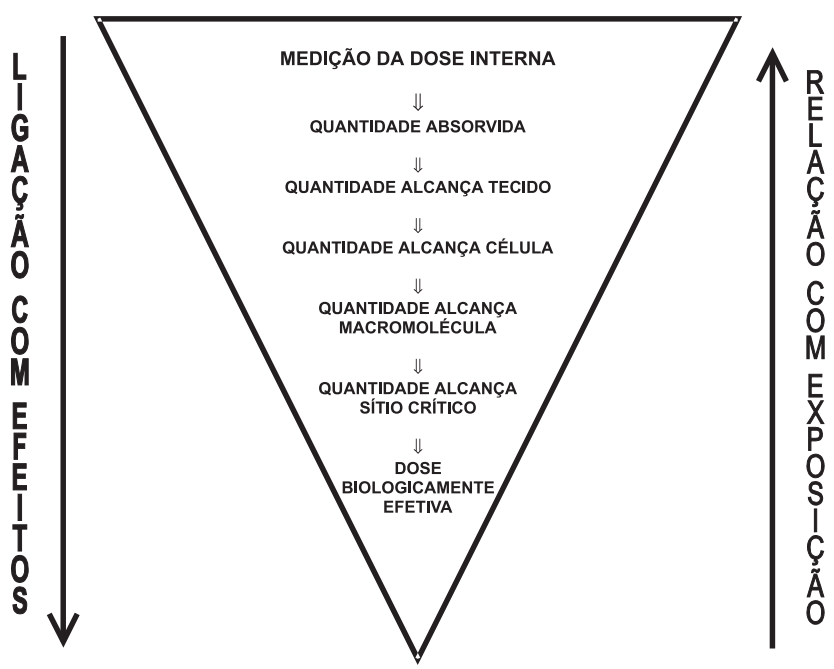

Figura 1 - Biomarcadores de dose interna das substâncias químicas, para as quais o principal mecanismo de interação ocorre através da interação molecular ${ }^{7}$

Figure 1 - Biomarkers of internal dose of chemical substances, whose major interaction mechanism is molecular interaction ${ }^{7}$

Dependendo da substância química e do parâmetro biológico analisado, o termo "dose interna" pode abranger diferentes concepções. O biomarcador de dose interna pode refletir a quantidade absorvida imediatamente antes da amostragem, como, por exemplo, a concentração de um solvente no ar alveolar ou no sangue durante a jornada de trabalho de indivíduos expostos; pode refletir a quantidade absorvida no dia anterior, como, por exemplo, a concentração do solvente no ar alveolar ou no sangue coletados 16 horas após o final da exposição; ou refletir a quantidade absorvida durante meses de exposição, quando a substância tem um tempo de meia vida longo, como, por exemplo, a concentração de alguns metais no sangue ${ }^{4,8}$.

A dose interna pode significar também a quantidade da substância química armazenada em um ou vários compartimentos do organismo ou distribuída em todo o organismo. Isto geralmente se aplica aos agentes tóxicos cumulativos ${ }^{4,8}$. Por exemplo, a concentração dos inseticidas organoclorados no sangue reflete a quantidade acumulada no principal sítio de depósito (tecido adiposo).

Por último, como uma forma ideal, a dose interna pode representar a dose "verdadeira”, ou seja, a quantidade da substância ligada ao sítio alvo ou biodisponível para interagir. Estes indicadores podem ser viáveis quando o órgão crítico for acessível (por exemplo, a hemoglobina, no caso da exposição ao monóxido de carbono) ou quando o agente tóxico interage com constituintes do sangue de forma similar aos constituintes do órgão crítico (por exemplo, alquilação da hemoglobina, refletindo a ligação com DNA no tecido alvo). Neste caso, a dose interna pode ser o produto da interação entre um xenobiótico e alguma molécula crítica ou célula, como a medição dos aductos covalentes formados com a substância química e que podem ser mensurados num compartimento dentro do organismo ${ }^{4,8}$. No entanto, a maioria dos indicadores biológicos de dose interna refletem apenas a exposição, ou seja, a quantidade absorvida do toxicante no organismo.

Para escolha do indicador biológico de dose interna mais adequado a uma situação 
específica de exposição, é necessário o conhecimento do comportamento cinético do agente químico presente no ambiente. Além disso, é necessário o conhecimento do tempo de permanência da substância química no organismo para a definição do momento ideal para a coleta. Alguns biomarcadores de dose interna, como benzeno no sangue, ácido hipúrico na urina, 2,5 hexanodiona na urina, refletem apenas a exposição recente ao benzeno, tolueno e n-hexano, respectivamente. Enquanto outros, como chumbo e mercúrio, após a quelação, refletem a exposição média dos últimos meses, e o cádmio na urina reflete a exposição dos últimos $\operatorname{anos}^{4,8}$.

\section{Biomarcadores de efeito}

O Biomarcador de Efeito é um parâmetro biológico, medido no organismo, o qual reflete a interação da substância química com os receptores biológicos. Muitos biomarcadores de efeito são usados na prática diária para confirmar um diagnóstico clínico. Mas, para o propósito da prevenção, um biomarcador de efeito considerado ideal, é aquele que mede uma alteração biológica em um estágio ainda reversível (ou precoce), quando ainda não representa agravo à saúde .

Geralmente, as alterações bioquímicas são consideradas como uma fonte potencial de indicadores biológicos de efeito. Se considerarmos que estas alterações precedem um dano estrutural, a detecção destas alterações biológicas permite a identificação precoce de uma exposição excessiva e intervenção para prevenir um efeito irreversível, ou seja, a doença. Esta estratégia é baseada na identificação das alterações bioquímicas precoces e reversíveis que são indicadores sensíveis e específicos de uma resposta do organismo à exposição. A extensão em que estes biomarcadores vão predizer uma resposta mais avançada (como doença ou risco de doença) requer necessariamente mais pesquisas e evidências através de estudos epidemiológicos ${ }^{6}$.

Em geral, um marcador precoce no progresso de uma resposta do organismo tem uma associação menor com o dano; no entanto é mais útil a sua aplicação com o propósito de prevenir a doença (Figura 2). Para a ação preventiva de uma exposição excessiva (ou que provoca danos à saúde), o efeito biológico medido, que é um biomarcador, tem que ser, necessariamente, um efeito não adverso ${ }^{4}$.

A distinção entre um efeito biológico adverso e um efeito biológico não adverso nem sempre é clara e algumas vezes tornase arbitrária devido à dificuldade de se avaliar o alcance do efeito na saúde. Entretanto, considera-se a ocorrência de efeitos não adversos quando ${ }^{7}$ :

- ao serem produzidos numa exposição prolongada, não resultem em transtornos da capacidade funcional nem da capacidade do organismo para compensar nova sobrecarga;

- são reversíveis e não diminuem perceptivelmente e capacidade do organismo

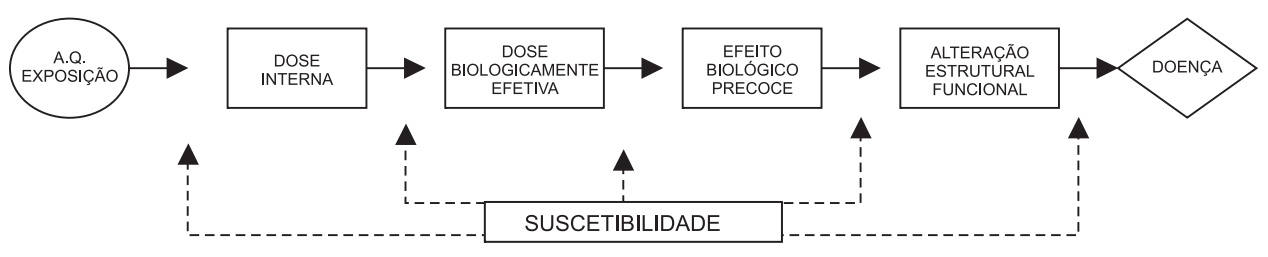

Figura 2 - Diagrama esquemático dos indicadores biológicos, indicando uma resposta progressiva do organismo à uma exposição à um agente químico (A.Q.) e os fatores de suscetibilidade que podem influenciar as etapas desta progressão ${ }^{6}$

Figure 2 - Diagram of biological indicators, showing a progressive response of the body to exposure to a chemical agents (CA) and susceptibility factors that may affect the stages of prograssion ${ }^{6}$ 
de manter sua homeostase orgânica;

- não aumentam a suscetibilidade do organismo aos efeitos indesejáveis e a outros fatores de risco ambiental.

Dentre os indicadores biológicos de efeito tem-se a carboxiemoglobina, a atividade da enzima colinesterase eritrocitária, níveis de enzimas e intermediários da biossíntese do HEME, de proteínas na urina etc. Cada um apresenta características diferentes segundo a sua especificidade. Por exemplo ${ }^{4}$ :

- Carboxiemoglobina (COHb): a COHb, apesar de ser um biomarcador de efeito, apresenta uma correlação muito significativa com a exposição ambiental ao monóxido de carbono, e reflete a dose interna deste toxicante ligado ao tecido alvo;

- Colinesterases: a determinação da atividade das enzimas colinesterase eritrocitária e colinesterase plasmática em indivíduos expostos aos inseticidas organofosforados e/ou carbamatos é utilizada também para o diagnóstico e o tratamento das intoxicações. Entretanto, não apresenta correlação muito significativa em exposições ambientais e/ou ocupacionais leves ou moderadas a estes inseticidas. Ainda assim, é considerado o indicador biológico de escolha.

- Enzima ácido delta amino-levulínico (ALA-D) nos eritrócitos: esta enzima é altamente sensível à inibição pelo chumbo. Em uma concentração de chumbo na faixa de 5 a $40 \mathrm{mg} / \mathrm{dL}$ já é possível observar uma correlação negativa entre a ALA-D e o $\mathrm{Pb} /$ sg. Por isso, representa um adequado indicador de efeito para exposição ambiental ao chumbo.

- Ácido delta amino-levulínico (ALA) na urina: devido à inibição da ALA-D pelo chumbo, o ALA se acumula nos tecidos e é excretado em grande quantidade na urina. No entanto, este biomarcador apresenta correlação com concentrações $\mathrm{de} \mathrm{Pb} / \mathrm{sg}$ acima de 40ug/dL, mostrando uma sensibilidade diferente da enzima. Por isso, é considerado mais adequado para avaliar a exposição ocupacional a este metal.
Alguns indicadores biológicos de efeito possibilitam a avaliação da ação de uma substância química no orgão alvo (ou sítio crítico) a partir da medida de uma alteração biológica associada a esta ação. No entanto, esta medida pode ter como limitação a dificuldade de acesso a certos tecidos do organismo. Embora sejam parâmetros importantes para prevenir possíveis efeitos nocivos à saúde, não são, em sua maioria, específicos para as substâncias químicas envolvidas, $\mathrm{e}$ por isso requerem pesquisas com o propósito de validação dos mesmos. Alguns exemplos são descritos abaixo:

\section{Biomarcadores de nefrotoxicidade}

Vários tipos de parâmetros têm sido testados e usados como biomarcadores de dano renal. Estes têm sido classificados como $^{10}$ :

- marcadores funcionais (por exemplo, creatinina sérica e $\beta_{2}$ - microglobulina);

- proteínas de baixo ou alto peso molecular (por exemplo, albumina, transferina, globulina ligada ao retinol);

- marcadores de citotoxicidade (por exemplo, antígenos tubulares);

- enzimas urinárias (por exemplo, Nacetilglicosaminidade, $\beta$-galactosidade).

Os biomarcadores de nefrotoxicidade foram bem validados em relação à exposição ao cádmio; no entanto, não têm evidências científicas suficientes para a exposição ao mercúrio e chumbo ${ }^{10,11}$.

\section{Biomarcadores de hepatoxicidade}

Os efeitos de substâncias químicas no fígado têm sido estimados tradicionalmente por determinação da atividade de várias enzimas, como, por exemplo, aminotransferases, álcool desidrogenase, lactato desidrogenase, glutationa-S-transferase, entre outras ${ }^{7}$.

A hepatotoxicidade é causada por várias substâncias que são metabolizadas pelo Sistema Citocromo P-450 a intermediários reativos. Por exemplo, para o tetracloreto de carbono, tem sido extensivamente estudada e bem documentada a sua ação 
hepatotóxica. O metabólito reativo do tetracloreto de carbono inicialmente reduz a glutationa peroxidade (GPX) intracelular a um nível que predispõe a reação do metabólito com macromoléculas críticas, levando à morte celular e à hepatoxicidade. Neste caso, os biomarcadores de efeito poderiam incluir níveis de glutationa, peroxidação lipídica ou número de células necrosadas ${ }^{7,12}$. Estes biomarcadores de hepatotoxicidade também estão associados à exposição ao cromo VI no estudo de Huang (1999) ${ }^{13}$.

\section{Biomarcadores de genotoxicidade}

Técnicas sensíveis baseadas em métodos físicoquímicos ou imunoquímicos para a detecção de uma variedade de substâncias conhecidas como carcinogênicas têm sido desenvolvidas. Entre estas estão incluídas as aflatoxinas, os hidrocarbonetos policíclicos aromáticos, as aminas aromáticas, e os praguicidas?

Estes biomarcadores incluem os aductos de DNA e proteína (aductos de hemoglobina e albumina), que se referem à ligação do xenobiótico ou de seu metabólitos a estas moléculas, formando os aductos ${ }^{6,14}$. Tendo em vista que os aductos constituem a própria substância química ligada ao sítio alvo, os mesmos são também considerados como biomarcadores de exposição ou dose interna.

\section{Biomarcadores de neurotoxicidade}

A complexidade das funções do sistema nervoso, os eventos neurotóxicos de natureza múltipla e a variabilidade e inacessibilidade dos sítios celulares e moleculares deste órgão são fatores que limitam o estabelecimento de indicadores para se avaliar a ação neurotóxica das substâncias químicas. Acrescente-se a estes fatores, o fato de os efeitos neurotóxicos, em geral, se iniciam tardiamente, após exposições prolongadas ou mesmo, após um período de latência, depois de terminada a exposição. Neste sentido, tem-se procurado validar alguns parâmetros que possam permitir a detecção precoce da ação neurotóxica, antes que seja evidenciado um dano à saúde do indivíduo exposto, seja por exposição ocupacional ou ambiental, considerando principalmente as crianças. São vários os indicadores utilizados para se avaliar o risco e a exposição a uma substância neurotóxica. Alguns estudos abordam três enfoques ${ }^{15,16,17}$ :

\section{Enfoque neurofisiológico}

O enfoque neurofisiológico, como o estudo da condução nervosa, o eletroencefalograma etc., é bastante útil no diagnóstico de desordens neurológicas, mas a utilização destes parâmetros na identificação dos efeitos neurológicos iniciais é ainda pouco estabelecida e por isso apresenta um baixo valor preditivo. Quanto à avaliação clínica, a mesma deve ser realizada com base num protocolo muito bem detalhado ${ }^{15,18}$.

\section{Enfoque neurocomportamental}

Métodos para avaliar alterações de funções cognitivas, como, por exemplo, aprendizagem e memória, têm sido extensivamente utilizados em indivíduos expostos a solventes e metais pesados. No entanto, em relação aos testes neurocomportamentais, estes podem estar alterados por motivos outros que não por ação de um xenobiótico. Por isso, para concluir sobre uma ação neurotóxica através de testes neurocomportamentais, estes devem ser extremamente bem delimitados e interpretados ${ }^{15,19,20}$.

\section{Enfoque neuroquímico}

No enfoque neuroquímico, várias evidências experimentais mostram que, na progressão de doenças neurotóxicas, os eventos bioquímicos precedem as alterações estruturais e danos permanentes ao SNC. Dessa forma, a medida destas alterações poderiam fornecer informações úteis sobre os efeitos precoces (ou iniciais) detectáveis, imediatamente antes ou logo após o início da doença (intoxicação) ${ }^{15,16,17}$.

Em geral, os eventos bioquímicos que ocorrem no Sistema Nervoso são considerados como potenciais biomarcadores; no entanto, a principal limitação da medida destes parâmetros é a inacessibilidade do tecido alvo. Geralmente, no Sistema Nervoso 
Central, muitos precursores e produtos são recicláveis e retidos no local. Além disso, as mudanças que acompanham a função neurológica ocorrem dentro de um pequeno espaço intra ou extra celular do próprio órgão, o que leva à impossibilidade de se implementar as rotinas de análises dos mesmos. Diante disso, uma nova metodologia de biomarcadores tem sido desenvolvida, procurando alcançar os propósitos da avaliação de risco à saúde, utilizando tecidos mais acessíveis para determinar indicadores "substitutos" daqueles localizados no tecido nervoso ${ }^{15,16}$.

Por isso, tem-se observado que alguns parâmetros bioquímicos e moleculares, semelhantes aos envolvidos na ação tóxica ocorrida dentro do SNC, podem estar presentes em tecidos mais acessíveis, como fluído cerebral espinhal, sangue, plasma e células sangüíneas. Alguns destes parâmetros são $0^{15}$ : Receptores:

- Receptores muscarínicos da Acetilcolina em linfócitos

- Receptor sigma; receptor Beta e alfa2 em plaquetas

Enzimas:

- Acetilcolinesterase eritrocitária

- Esterase neurotóxica em linfócitos

- $\mathrm{MAO}$ - tipo B em plaqueta

- Dopamina Beta hidoxilase no soro

Sistema de recaptação:

- 5-Hidroxindolacático (serotonina) em plaquetas

\section{Transdução do sinal nervoso:}

- Concentração de cálcio intracelular

- Fosfoinositol em plaquetas e linfócitos A medida destes parâmetros permite avaliar, através de métodos acessíveis, a ação de um agente químico no sistema nervoso central, os quais são denominados Indicadores Substitutos de Neurotoxicidade ou, simplesmente, Marcadores Substitutos. O estudo destas alterações bioquímicas pode possibilitar a oportunidade de se identificar precocemente uma exposição excessiva e avaliar a neurotoxicidade para prevenir o aparecimento de efeitos ou danos irreversíveis ${ }^{21,22}$.

Entretanto, a escolha dos indicadores substitutos não é fácil e nem sempre é possí- vel. É necessário que estes parâmetros periféricos sejam equivalentes ou então correlacionados funcionalmente ao parâmetro correspondente no SNC. Esta correspondência deve ser comprovada através de estudos experimentais que demonstrem que o parâmetro sob investigação tenha a mesma característica bioquímica e funcional daquele presente no SNC; e que as alterações quimicamente induzidas neste parâmetro ocorrem do mesmo modo nos dois sistemas (periférico e nervoso) ${ }^{15}$.

Posteriormente, a comprovação de que tal marcador biológico substituto é preditivo para determinado xenobiótico (seja para avaliar risco ou doença), requer necessariamente mais pesquisas, incluindo vigilância epidemiológica e estudos prospectivos para a validação dos mesmos. Vários trabalhos ${ }^{23-}$ ${ }^{30}$ têm apresentado, ultimamente, contribuições e discussões sobre o uso destes marcadores periféricos (ou marcadores substitutos) de neurotoxicidade, nos quais vários autores apontam a necessidade de se incluir a avaliação de outros parâmetros de neurotoxicidade, como as alterações neurocomportamental, neurofisiológica e neuroclínica.

\section{Biomarcadores de suscetibilidade}

Por que alguns indivíduos adoecem e outros não?

A predisposição genética, além de fatores externos, tais como idade, dieta, estilo de vida, podem influenciar/afetar a suscetibilidade de indivíduos expostos a substâncias químicas?.

Embora alguns indivíduos experimentem exposição ambiental similar, diferenças genéticas no metabolismo podem produzir doses marcadamente diferentes no sítio crítico e, conseqüentemente, nível diferente de resposta. Até mesmo quando as doses críticas são similares, respostas diferentes podem ser notadas nos indivíduos devido a variações na suscetibilidade biológica. Os biomarcadores de suscetibilidade podem refletir fatores genéticos ou adquiridos que influenciam na resposta do organismo a uma determinada exposição química. Estes são 
fatores pré-existentes e independem da exposição. São predominantemente genéticos, embora a patologia, alterações fisiológicas, medicamentos e exposição a outros agentes ambientais também possam alterar a suscetibilidade individual. Os biomarcadores de suscetibilidade identificam aqueles indivíduos na população que têm uma diferença genética ou adquirida na suscetibilidade para os efeitos da exposição a substâncias químicas ${ }^{6,7,31}$.

Os biomarcadores de suscetibilidade indicam quais os fatores podem aumentar ou diminuir um risco individual no desenvolvimento da resposta do organismo decorrente da exposição aos agentes químicos ambientais. A Tabela 1 mostra alguns biomarcadores de suscetibilidade estabelecidos (e/ou propostos) para alguns agentes químicos ${ }^{6}$.

\section{Níveis de ação}

A presença e evidência de um risco químico num ambiente são reconhecidas com base nos limites permissíveis no meio biológico, os quais são propostos a partir das informações obtidas nos estudos de toxicidade, através das relações dose-resposta, e reconhecidos como níveis de advertência. Os mesmos não devem ser considerados como valores que separam exposições seguras de exposições perigosas. Eles são estabelecidos de diferentes maneiras, dependendo de sua origem (país e/ou instituição), através $\mathrm{de}^{7}$ :
- estudos epidemiológicos, clínicos e experimentais que estabelecem a relação entre a concentração medida de um agente ou de seu metabólito num meio biológico com conseqüências para a saúde. São níveis de ação da biomonitorização relacionados diretamente com a saúde; ou

- derivados matematicamente dos limites de exposição ocupacional, ou seja, representam a concentração da substância química ou de seu metabólito, que deverá estar presente na amostra biológica coletado de um trabalhador exposto ao limite máximo permitido no ambiente.

No Brasil, os Limites Biológicos de Exposição são estabelecidos para os Biomarcadores de exposição e de efeito para substâncias químicas presentes no ambiente de trabalho, os quais constam do Quadro I da Norma Regulamentadora $\mathrm{n}^{\mathrm{o}} 7^{32}$, onde constam os respectivos valores de referência para indivíduos não expostos ocupacionalmente. Estes limites foram atualizados em 1994, recebendo a denominação de Índice Biológico Máximo Permitido, e são estabelecidos para apenas 26 substâncias químicas.

No que se refere à exposição ambiental, as concentrações aceitáveis são referenciadas em Normas Internacionais e na comunidade científica. Entretanto, deve ser considerado que algumas desta normas podem não ter como base estudos de toxicidade confiáveis e adequados e não serem apropriadas para indivíduos sensíveis (crianças, idosos, enfermos) ou para exposições

Tabela 1 - Biomarcadores de suscetibilidade para alguns agentes químicos ${ }^{6}$ Table 1 - Biomarkers of susceptibility for some chemical agents ${ }^{6}$

\begin{tabular}{ll}
\hline BIOMARCADOR DE SUSCETIBILIDADE & AGENTE QUÍMICO/EFEITO \\
\hline Glicose 6-P desidrogenase (deficiência) & $\begin{array}{l}\text { Compostos nitroaromáticos/baixa resistência p/ } \\
\text { estresse oxidativo }\end{array}$ \\
\hline Glutationa-S-transferase & $\begin{array}{l}\text { Óxido de etileno, compostos alifáticos } \\
\text { halogenados/diminuição da detoxificação dos } \\
\text { intermediários epóxidos }\end{array}$ \\
\hline Paroxonase & $\begin{array}{l}\text { Organofosforados/aumenta a toxicidade dos OF } \\
\text { diminuindo a atividade da AchE }\end{array}$ \\
\hline
\end{tabular}


contínuas. Por isso, torna-se pertinente a realização de estudos ambientais utilizando estes parâmetros biológicos na avaliação do risco químico.

\section{Considerações finais}

Os biomarcadores, sejam de exposição ou de efeito, são ferramentas utilizadas nos estudos epidemiológicos ambientais, buscando-se estabelecer uma relação entre a exposição aos agentes químicos e os efeitos na saúde dos indivíduos expostos. A importância do uso destes biomarcadores como parâmetros biológicos de exposição às substâncias químicas deve-se ao fato de eles estarem mais diretamente relacionados aos efeitos na saúde do que os parâmetros ambientais. Por isso, podem oferecer uma melhor estimativa do risco.

A avaliação biológica leva em consideração a absorção por diferentes vias e rotas de exposição de um agente químico, permitindo avaliar a exposição global do indivíduo ou população.

Em relação aos efeitos das substâncias neurotóxicas, o uso de biomarcadores substitutos permite a associação com a exposição a baixos níveis, fornecendo conhecimentos e evidências científicas necessários para a aplicação de medidas de prevenção e controle da exposição aos agentes químicos ambientais no âmbito das políticas públicas.

\section{Referências}

1. World Health Organization - International Programme on Chemical Safety (IPCS) - Environmental Health Criteria 214: Human exposure assessment, Geneva; 2000 .

2. Koning HW. Estabelecimiento de Normas Ambientales - Pautas para la adopción de Decisiones. Organización Mundial de la Saúde - OMS, Geneva; 1998.

3. Bernard A, Lauwerys R. Assessment of human exposure to chemicals through biological monitoring. In: Kopfler FC, Craun, GF (eds). Environmental Epidemiology. Chelsea: Lewis Publ. Inc.; 1986. p.17-28.

4. World Health Organization - Biological Monitoring of Chemical Exposure in the Workplace. Volumes 1 e 2. Geneva; 1996.

5. Dougherty J. Employee health monitoring data bases and their role in defining the safety of chemical products. Int Arch Occup Environ Health 1998; 71: 101-3.

6. Rüdiger HW. Biomonitoring in occupational medicine. In: Marquart H, Schäfer SG, McClellan R, Welsch F (eds.). Toxicology. San Diego: Academic Press; 1999. p.1027-39.

7. World Health Organization - International Programme on Chemical Safety (IPCS) - Environmental Health Criteria 155: Biomarkers and risk assessment: concepts and principles. Geneva; 1993.
8. Lauwerys R.R. - Industrial Chemical Exposure Guidelines for Biological Monitoring. 2a ed. London: Lewis Publishers; 1993.

9. World Health Organization - International Programme on Chemical Safety (IPCS) - Environmental Health Criteria 210: Principles for the assessment of risks to human health from exposure to chemicals. Geneva; 1999.

10. World Health Organization - International Programme on Chemical Safety (IPCS) - Environmental Health Criteria 119: Principles and methods for the assessment of nephrotoxicity associated with exposure to chemicals. Geneva; 1991.

11. Roels $\mathrm{H}$ et al. Markers of early renal changes induced by industrial pollutants. Applications to workers exposed to cadmium. Br J Ind Med 1993; 50: 37-48.

12. Yiin SJ, Lin TH, Shih TS. Lipid peroxidation in workers exposed to manganese. Scand J Work Environ Health 1996; 22(5): 381-6.

13. Huang Y. Lipid peroxidation in workers exposed to hexavalent chromium. J Toxicol Environ Health A 1999; 56: $235-47$.

14. Hemminki K. DNA adducts in biomonitoring. J Occup Environ Med 1995; 37: 44-9. 
15. Manzo L et al. Biochemical markers of neurotoxicity. Areview of mechanistic studies and applications. Human \& Experimental Toxicology 1996; 15(1): 20-35.

16. Costa LG. Biochemical and molecular neurotoxicology: relevance to biomarker development, neurotoxicity testing and risk assessment. Toxicol Lett 1998; 102-103: 417-21.

17. Silbergeld EK. Neurochemical approaches to developing biochemical markers of neurotoxicity: review of current status and evaluation of future prospects. Environ Res 1993; 63: 274-86.

18. Hawkins KA. Occupational neurotoxicology: some neuropsychological issues and challenges. Journal of Clinical and Experimental Neuropsychology 1990; 12(5):664-80.

19. Johnson BL. Neurobehavioral toxicology in the $21^{\text {st }}$ century: a future or a failure?. Environ Res 1993; 62: 114-24.

20. Iregren A. Using psychologial tests for early detection of neurotoxic effects of low level manganese exposure. Neurotoxicology 1994; 15: 671-8.

21. Mergler D, Baldwin M. Early manifestations of manganese neurotoxicity in humans: an update. Environ Res 1997; 73: 92-100.

22. Castoldi A et al. Biomarkers in environmental medicine: alterations of cell signalling as early indicators of neurotoxicity. Funct Neurol 1994; 9: 101-9.

23. Baldwin $\mathrm{M}$ et al. Bioindicator and exposure data for a population based study of manganese. Neurotoxicology 1999; 20(2-3): 343-53.

24. Costa LG, Manzo L. Biochemical markers of neurotoxicity; research strategies and epidemiological application. Toxicol Lett 1995; 77: 137-44.
25. Costa LG. Biomarker research in neurotoxicology: the role of mechanistic studies to bridge the gap between the laboratory and epidemiological investigation. Environ Health Perspect 1996; 104(1): 55-67.

26. Smargiassi A, Mutti A. Peripheral biomarkers and exposure to manganese. Neurotoxicology 1993; 20(23): 401-6.

27. Smargiassi A, Mutti A. Selective vulnerability of dopaminergic systems to industrial chemicals: risk assessment of related neuroendocrine changes. Toxicol Ind Health 1998; 14(1-2): 311-23.

28. Romberg L. Use of biomarkers in quantitative risk assessment. In: Travis CC (ed.). Use of Biomarkers in Assessing Health and Environmental Impact of Chemical Pollutants. New York: Plenum Press; 1993.

29. Jadhav AL, Ramesh GT. Pb-induces alterations in tyrosine hydroxilase activity in rat brain. Mol Cell Biochem 1997; 175: 137-41.

30. Kala SV \& Jadhav AL. Low level lead exposure decreases in vivo release of dopamine in rat nucleus accumbens: a microdialysis study. J Neurochem 1995; 65(4): 1631-5

31. Akgür AS. Paraoxonase and acetylcholinesterase activities in humans exposed to organophosphorous compounds. J Toxicol Environ Health A 1999; 58: 469 74 .

32. BRASIL. Ministério do Trabalho. Secretaria de Segurança e Higiene e Medicina do Trabalho. Segurança e Medicina do Trabalho: Lei n. 6514, de 22 de dezembro de 1997, normas regulamentadoras (NR) aprovadas pela Portaria 3214, de 8 de junho de 1978. 43.ed. São Paulo: Atlas; 1999.

Recebido em: 24/07/2002 Aprovação em: 29/10/2002 